\title{
Clinical Trial Management Tracking Documentation
}

National Cancer Institute

\section{Source}

National Cancer Institute. Clinical Trial Management Tracking Documentation. NCI

Thesaurus. Code C115658.

Records detailing the progress of clinical trial activities. 